\title{
A violência doméstica contra o idoso identificada em um programa de assistência domiciliar: estudo de caso $^{1}$
}

\author{
Domestic violence against two aged people attended by the \\ interdisciplinary home attendence: case study
}

\section{La violencia doméstica contra ancianos identificadas en un programa de asistencia domiciliar: estudio de caso}

\author{
Maria do Rosário Menezes', Noélia Assis de Oliveira", Larissa Chaves Pedreira"', \\ Elaine Cristina Santos ${ }^{\prime \vee}$, Maria Luiza Dias ${ }^{\vee}$
}

\begin{abstract}
RESUMO
Esse trabalho é recorte de ampla pesquisa sobre violência doméstica contra idosos na cidade do Salvador - Bahia, teve como objetivo apresentar e analisar a prática de violência familiar contra dois idosos, assistidos pelo Programa de Atenção Domiciliar Interdisciplinar (PADI) do Serviço Médico Rubens Brasil da Universidade Federal da Bahia (SMURB/UFBA). Estudo qualitativo, exploratório e descritivo, tipo estudo de caso. Os dados foram obtidos a partir das anotações sobre os idosos registradas nos prontuários, colhidas durante as visitas domiciliares entre outubro e dezembro de 2006. Dos casos, foram extraídas três categorias: agressão física; abuso financeiro-material e negligência do cuidado humano e ambiental, analisadas através da análise de conteúdo de Bardin e de acordo com a literatura sobre o tema. Essas situações levaram a inferir que fatores sociais, econômicos, políticos, culturais, e a falta de um processo afetivo humano, somado a co-responsabilidade, ao compromisso e à solidariedade intergeracional, podem negligenciar ou privar os idosos do direito de serem cuidados na família. Fica evidente a necessidade de formação e capacitação de profissionais de saúde, capazes prevenir e intervir junto a idosos, vítimas da violência doméstica e seus familiares, a fim de promover a saúde e garantir os direitos dos idosos contidos na Lei.
\end{abstract}

Palavras chave: Violência doméstica; Maustratos ao idoso; Serviços de assistência domiciliar.

\section{ABSTRACT}

This work, fragment of a wide research about domestic violence against aged people in Salvador city - Bahia, had the objective to present and analyze the practice of family violence against two aged people attended by the Interdisciplinary Home Attendance (PADI) of the Federal University of Bahia Medical Service (SMURB). This is a qualitative, exploratory and descriptive study, of case study type. The data were obtained after the history of the aged people, collected during the home visits. From the talks were extracted three categories: physical aggression; material-financial abuse and negligence in the human and environmental care, evaluated through the analysis of the content of Bardin, and according to the literature about the theme. This situation led to infer that besides the social, economic, political and cultural factors, the lack of an affective human process added to co-responsibility, to the compromise and to the inter-generation solidarity, may neglect or deprive the aged people from the right of being cared in the family. Is evident a need of formation and training of the health professionals able to act to preview and effectively intervene with aged people victims of domestic violence and their relatives, with the aim of promoting the health, guaranteeing to the aged people fundamental rights contained in the Law.

\footnotetext{
Recorte do Projeto de Pesquisa Intitulado Revelando a violência doméstica contra idosos na cidade do Salvador, Bahia, do Grupo de Estudos e Pesquisas sobre Violência, Saúde e Qualidade de Vida da EEUFBA.

Professora Adjunta da Escola de Enfermagem da Universidade Federal da Bahia (Brasil) (EEUFBA). Doutora em Enfermagem (USP). Coordenadora do Grupo de Estudos sobre Violência em Idosos da EEUFBA. E-mail: menezes@ufba.br.

"Enfermeira, Mestre em Enfermagem pela UFBa, integrante da equipe de criação e implantação do PADI, enfermeira de referência do Programa de Atenção Domiciliar Interdisciplinar (PADI). E-mail: n.assis@terra.com.br.

III Professora Assistente da EEUFBA. Doutoranda em Enfermagem. Integrante do Grupo de Estudos e Pesquisas sobre o Cuidar da EEUFBA. E-mail: Ichavesp@ufba.br.

IV Especialista em Gerontologia, Enfermeira assistencial do PADI.

${ }^{\vee}$ Enfermeira. Mestre em Enfermagem pela UFBA, integrante da equipe de criação e implantação do PADI, enfermeira do PADI, Diretora do Serviço Médico Universitário.
} 
Menezes MR, Oliveira NA, Pedreira LC, Santos EC, Dias ML. A violência doméstica contra o idoso identificada em um de assistência domiciliar: estudo de caso. Rev. Eletr. Enf. [Internet]. 2008;10(4):1050-6. Available from: http://www.fen.ufg. br/revista/v10/n4/v10n4a17.htm.

Key words: Domestic violence; Elder abuse; Home care service.

\section{RESUMEN}

Este trabajo, recorte de una amplia pesquisa sobre violencia doméstica contra ancianos en la ciudad de Salvador de Bahía, tuvo como objetivo presentar y analizar la práctica de la violencia familiar contra dos ancianos, asistidos en el Programa de Atención Domiciliar Interdisciplinario (PADI) de lo Servicio Medico Rubens Brasil de la Universidad Federal de Bahía (SMURB/UFBA). Estudio de carácter cualitativo, exploratorio, descriptivo, tipo estudio de caso. Los dados fueron obtenidos la partí de las anotaciones sobre los ancianos registradas en los prontuarios, cogidas durante las visitas domiciliares en el periodo de octubre a diciembre de 2006. De los casos, fueron extraídas tres categorías: agresión física; abuso financiero/material, negligencia de lo cuidado

\section{NTRODUÇÃO}

A violência contra o idoso, tem uma grande relação com o poder exercido pelos mais jovens sobre este, principalmente com o modelo cultural que super valoriza as idades mais novas. Assim, é apontado que a violência contra essas pessoas no domicilio, tem uma freqüência maior e é mais grave do que se supõe $e^{(1)}$.

Os abusos no âmbito familiar são omitidos tanto pelo agressor, como pelo agredido, entre estes estão as negligências físicas, financeiras, psicológica, nutricional e sexual, assim como a violação aos direitos dos idosos e o não atendimento às suas necessidades básicas ${ }^{(2)}$.

Sobre a classificação dos maus tratos contra idosos, o Informe Mundial sobre la Violencia y la Salud ${ }^{(3)}$, destaca que durante uma oficina realizada no Sul da África em 1992, se estabeleceu uma distinção entre vexação (maltrato verbal, descuido passivo, exploração econômica e excesso de medicação) e maus tratos (violência física, psíquica, sexual e roubo). Desde então, reuniões têm sido realizadas com grupos de idosos deste país, com o objetivo de determinar o nível de conhecimento e de compreensão do fenômeno dos maus tratos de idosos nessas comunidades.

Assim, além do típico esquema ocidental, que compreende o maltrato físico, verbal, econômico, abuso sexual e o descuido, os humano y ambiental, avaliados de acuerdo con el contenido de Badin y de acuerdo con la literatura sobre el tema. Esas situaciones levaran la inferir que los factores sociales, económicos, políticos y culturales, la falta de un proceso efectivo humano, sumado a responsabilidad mutua, a lo compromiso y a solidariedad intergeracional, pueden negligenciar o privar los ancianos del directo de ser cuidados en la familia. Es así evidente la necesidad de formación y capacitación de profesionales de salud capaces de actuar en la prevención y intervención efectivas junto a ancianos víctimas de la violencia domestica y sus familiares, con la finalidad de promover la salud y garantizar los directos de los ancianos.

Palabras clave: Violencia doméstica; Maltrato al anciano; Servicios de atención de salud a domicilio.

participantes agregaram outras definições como a falta de respeito pelos idosos, que se equipara com o descuido e o maltrato, infligido pelos sistemas (ambulatórios de previdência social e organismos burocráticos). Estas definições propostas pelos participantes e classificadas pelos investigadores, são resultados de uma tentativa realizada no Sul da África para obter informações sobre os maus tratos contra idosos, a partir deles ${ }^{(3)}$.

Quanto ao conceito de maus tratos contra idosos, a Rede Internacional para a Prevenção do Abuso ao Idoso ${ }^{(4)}$ o define como: “... a ação única ou repetida ou a falta de resposta apropriada, que ocorre dentro de qualquer relação onde exista uma expectativa de confiança, que cause dano ou angústia a uma pessoa idosa".

Para a Organização Mundial de Saúde ${ }^{(3)}$ o maltrato a essas pessoas é uma violação aos direitos humanos, se tornando uma causa importante de lesões, perda da produtividade, isolamento e depressão.

A Associação Médica Americana o define como "um ato ou omissão que resulta em dano ou ameaça de dano à saúde de uma pessoa idosa"(3). De acordo com uma pesquisa, dos 131 atestados de óbito analisados, 115 tiveram como causa de morte registrada a informação, "sem assistência médica", o que reflete as 
Menezes MR, Oliveira NA, Pedreira LC, Santos EC, Dias ML. A violência doméstica contra o idoso identificada em um de assistência domiciliar: estudo de caso. Rev. Eletr. Enf. [Internet]. 2008;10(4):1050-6. Available from: http://www.fen.ufg. br/revista/v10/n4/v10n4a17.htm.

lacunas existentes nas políticas de proteção ao idoso e na negligência velada contra essa população(2). Além disso, a faixa etária mais acometida foi a que se encontrava entre 71 e 80 anos, sendo mais fragilizada, com perdas funcionais e, portanto, mais susceptível a violência.

Outros trabalhos também apontam que as alterações funcionais e cognitivas, a fragilidade da idade e a ocorrência de doenças incapacitantes, são fatores de risco para maus tratos $^{(1-5)}$

Assim, o quadro observado nos estudos é que a classe mais acometida é a de baixa renda, com idade entre 65 a 82 anos; a maioria das violências foi praticada com o intuito de extorsão e apropriação indevida; os agressores em sua maioria tinham laços consangüíneos ou eram conhecidos, supondo-se que a intensidade da violência está relacionada à intimidade dos relacionamentos; a maioria dos agressores foram filhos, subempregados, desempregados e usuários de drogas ${ }^{(1-5)}$.

É apontado ainda que os idosos que dependem de cuidados de terceiros para sobreviver, fazem parte de um grupo de risco de sofrer abusos, onde $2 / 3$ destes são praticados pelo conjugue e o restante, pelos jovens ${ }^{(1)}$.

Trabalhando no Programa de Assistência Domiciliar Interdisciplinar (PADI) que presta assistência domiciliar à comunidade da Universidade Federal da Bahia (UFBA), em parceria com a Escola de Enfermagem da UFBA (EEUFBa) e o Serviço Médico Universitário Rubens Brasil (SMURB/UFBA), e atuando no Grupo de Estudos e Pesquisas sobre Violência, Saúde e Qualidade de Vida da EEUFBa, observamos alguns casos de violência contra idosos no domicílio, durante conversas e visitas domiciliares. Destes, dois nos chamaram a atenção, nos motivando selecioná-los para estudo.

Pesquisas como estas são importantes no sentido de alertar a equipe, pois a enfermagem é pouco preparada para identificar, avaliar e encaminhar casos tidos como violentos, principalmente quando estes ocorrem no domicílio ${ }^{(6)}$. Nesse ponto, o Código de Ética da Enfermagem $^{(5)}$ considera infração ética: "... provocar, cooperar ou ser conivente com maustratos" (Art. 52), sob penas que variam de uma simples advertência à cassação de direito de exercer a profissão.

Contudo, as principais dificuldades desses trabalhadores são: o despreparo para lidar com o paciente violentado, a falta de comprometimento institucional em relação ao apoio psicológico e a capacitação dos enfermeiros para lidar com essa violência ${ }^{(6)}$.

Esse estudo teve como objetivo apresentar e analisar a prática de violência familiar contra dois idosos assistidos pelo PADI.

É importante atentar para essas ocorrências que, muitas vezes, estão veladas ou camufladas, a fim de procurarmos formas de intervenção eficientes, que preservem a integridade e dignidade dessas pessoas.

\section{METODOLOGI A}

Pesquisa qualitativa, descritiva e exploratória tipo estudo de caso instrumental. Esse tipo de estudo de caso facilita a compreensão de algo mais amplo, "uma vez que pode servir para fornecer insight sobre um assunto"(7).

A coleta de dados utilizou como fonte, dados secundários dos prontuários de dois pacientes acompanhados pelo PADI, após consentimento do serviço por meio do Diretor da Unidade. Esta ocorreu entre outubro e dezembro de 2006, através dos registros em prontuário feitos pela equipe de assistência domiciliar.

O projeto maior, do qual essa pesquisa faz parte, intitulado: Revelando a violência doméstica contra idosos na cidade do Salvador, Bahia, foi submetido e aprovado pelo Comitê de Ética em Pesquisa, CEP-SESAB, protocolado com o número 021/2004. Destacamos que os prontuários da coleta de dados continham um Termo de Consentimento Livre e Esclarecido assinado pelos colaboradores, que autorizavam a utilização de seus dados para pesquisa. Esse termo se encontra anexado a todos os prontuários do serviço, sendo apresentado ao paciente e/ou família durante a admissão. O termo deixa claro, que sua recusa não implicará em nenhuma interferência na prestação do cuidado, e que o anonimato será garantido. 
Menezes MR, Oliveira NA, Pedreira LC, Santos EC, Dias ML. A violência doméstica contra o idoso identificada em um de assistência domiciliar: estudo de caso. Rev. Eletr. Enf. [Internet]. 2008;10(4):1050-6. Available from: http://www.fen.ufg. br/revista/v10/n4/v10n4a17.htm.

Após a leitura e investigação das informações contidas nos prontuários, os casos foram construídos e lidos, sendo seu conteúdo submetido à análise temática de conteúdo de Bardin $^{(8)}$. Segundo esse autor, a análise dá-se pela identificação de fragmentos cujas idéias constituintes remetem a determinados temas. A identificação desses temas permitiu a construção de três categorias: agressão física, abuso financeiro ou material, negligência do cuidado pessoal e do ambiente de moradia. Os dados foram discutidos à luz do referencial teórico adotado.

\section{Caso 1}

Masculino, 88 anos, divorciado, católico não praticante. Aposentado pela UFBA, com renda individual de aproximadamente 900 reais. Pai de 13 filhos com múltiplas companheiras. Procurou apoio dos membros da equipe do SMURB em 2004, relatando maus tratos no domicílio tipo empurrões, na tentativa de arrombamento do seu armário pela filha que mora com o mesmo, a fim de apropriar de sua renda mensal para arcar com todas as despesas da casa. Essa queixa, de acordo com o comunicante, foi levada à delegacia de polícia. O episódio induziu o idoso a procurar uma casa de acolhimento, entretanto, a interferência de uma sobrinha fez com que o mesmo fosse residir com ela. Esta informou ser o idoso uma pessoa considerada de difícil temperamento, tendo inclusive dificuldades para manter com assiduidade cuidadores contratados para assistência, e que não recebe atenção dos filhos. Atualmente encontra-se matriculado no PADI, com seqüelas de acidente vascular cerebral ( $A \vee C)$, hemiplégico à direita, com dificuldades de deambulação e dependente de cuidados de saúde. Voltou a residir com a família que anteriormente tentou extorquí-lo, pois se recusa a morar no abrigo.

\section{Caso 2}

Feminino, 81 anos, solteira, doméstica, católica não praticante, reside na casa da única filha, que é a atual cuidadora, em quarto anexo à residência principal, a qual acomoda, no período noturno, a neta. Deambula com dificuldade em conseqüência da seqüela provocada pelo AVC e pela obesidade. Após a visita domiciliar de rotina, foi observado que a idosa dorme em um quarto com precárias condições de higienização, ventilação e iluminação, dormindo com um felino, apesar de ter problemas respiratórios. Possui condições inadequadas de higiene pessoal, revelando um visível estado de negligência e abandono. Constatou-se, em relação a visitas anteriores, quando a paciente era assistida por um cuidador remunerado, que as condições de higiene pessoal e ambiental eram mais favoráveis, contudo esse teve que ser demitido por falta de condição da família em mantê-lo.

\section{RETRATOS DA VI OLÊNCI A DOMI CI LI AR}

A violência contra o idoso é um fenômeno mundial, que só recentemente vem sendo estudada no Brasil. As três categorias que se seguem, trazem o retrato de uma parte desta, que foi identificada nos casos apresentados.

\section{Agressão física}

Foi relatada no caso 1 , sendo definida como a coação física ou domínio induzido pela força ${ }^{(3)}$. A agressão física ocorrida parece ter acontecido em função da história de temperamento difícil do idoso, com expulsão de vários cuidadores e queixas da falta de atenção dos filhos que não se dispõem a cuidar dele. Observamos aqui, o quanto à construção de uma relação familiar forte, consistente, onde o carinho, amor e respeito convivem juntos, é importante em um momento como este.

A literatura aponta que nas relações intrafamiliares em que não existe o afeto que normalmente une pais e filhos, cônjugues e outros membros familiares (por não ter havido na construção de vida familiar relações fortalecedoras de vínculos, amizade, sentimentos humanos de amor ao próximo) ou casos em que esta relação não existiu (como filhos criados em outras famílias ou noras com breve ou sem relacionamento com o idoso a ser cuidado), podem ser fatores que levam o cuidador e o idoso em cuidado, a experimentar conseqüências negativas na relação de cuidado. Essa situação torna-se propícia para ocorrência de negligência ou maus-tratos ${ }^{(4-9)}$.

Nesse sentido, podemos inferir que a 
Menezes MR, Oliveira NA, Pedreira LC, Santos EC, Dias ML. A violência doméstica contra o idoso identificada em um de assistência domiciliar: estudo de caso. Rev. Eletr. Enf. [Internet]. 2008; 10(4):1050-6. Available from: http://www.fen.ufg. br/revista/v10/n4/v10n4a17.htm.

história pessoal, geracional e de parentesco que envolve os cuidadores e os idosos, também são determinantes importantes na relação que irá se estabelecer no processo de cuidar e ser cuidado. Nesta, estão envolvidos sentimentos de troca, reciprocidade, carinho entre outros. Esse intercâmbio entre gerações, é controlado também por fatores econômicos e ideológicos ${ }^{(7)}$.

\section{Abuso financeiro ou material}

Observado no caso 1 , ele é caracterizado por extorsão e controle do dinheiro da pensão.

Sobre os fatores de risco de maus tratos na relação idoso-cuidador, um estudo ${ }^{(5)}$ mostrou que $92 \%$ dos idosos com risco de sofrer maus tratos, eram beneficiários da previdência social, recebendo apenas um salário mínimo. Este também era constituído por um grupo de idosas, sobretudo viúvas, em processo de fragilização e dependência funcional, mas continuando a ser a pessoa de referência na família, por ser quase exclusivamente a principal provedora do sustento desta.

Assim, uma situação de risco elevado para violência contra o idoso é aquela em que o agressor é seu dependente econômico. Um protocolo de avaliação e risco de maus tratos em idosos, aponta que, uma das principais questões a se fazer na avaliação é: você auxilia no sustento de alguém ${ }^{(3)}$ ?

No Estatuto do Idoso, Capítulo II Dos crimes em espécie, Art. 102, é destacado que se apropriar de ou desviar bens, proventos, pensão ou qualquer outro rendimento do idoso, dando-Ihes aplicação diversa da sua finalidade, pode levar a reclusão de um a quatro anos e multa(11).

Sobre isso, uma pesquisa documental sobre maus tratos em idosos, revelou que das queixas registradas em um órgão oficial de denúncias contra violência, $27 \%$ destas estavam associadas à apropriação indébita de aposentadoria $^{(10)}$.

Essa situação, portanto, está de acordo com a literatura e denota uma realidade social atual, onde por conta do desemprego, a renda do idoso com a aposentadoria, tem sido a principal fonte mantenedora em muitas famílias.

\section{Negligência do cuidado pessoal e do ambiente de moradia}

A observação da negligência foi feita nos dois casos, onde houve deficiência nos cuidados de saúde. Ela se constitui uma recusa ou falha em desempenhar a obrigação de cuidar do idoso, podendo ou não envolver uma tentativa consciente ou intencional de infligir sentimento físico ou emocional a este ${ }^{(3)}$.

Ocorrências de maus tratos observadas em uma pesquisa mostraram que $67 \%$ destas se referiam a abandono do idoso, e dos que recebiam assistência da família, 38\% sofriam negligência por parte desta ${ }^{(10)}$.

A negligência pode ser ativa, quando o cuidador tem conhecimento dos cuidados adequados, porém não os utiliza, ou passiva, quando há falta de conhecimento dos cuidados apropriados por parte do cuidador $^{(1)}$. Nos casos citados, pode ter havido negligência ativa nos dois, já que o familiar, como é de rotina no programa, recebe da equipe acompanhamento e orientações quanto aos cuidados durante as visitas. Esta informação está registrada nos prontuários.

Com o envelhecimento, há uma diminuição da capacidade física e mental, das funções vitais e surgimento de doenças crônicas não transmissíveis. Por isso, a pessoa idosa, em alguma fase da sua vida, irá necessitar de cuidados de saúde diretos ou não.

Os idosos do estudo possuem idade superior a 80 anos, quando algumas dificuldades relacionadas ao desenvolvimento das atividades básicas e instrumentais da vida diária podem se intensificar ou aparecer como as deficiências auditivas, visuais, de deambulação, de realização da higiene pessoal, entre outras. Nos casos apresentados, estes são portadores de seqüelas de AVC, possuem dificuldades de locomoção, deficiências visuais, limitações para desenvolver o autocuidado e necessitam de auxílio para o uso da medicação.

A esse respeito, uma pesquisa mostra a ocorrência de doença crônica não transmissível com alguma dependência, como um fator de risco para maus tratos. Em 50 idosos dependentes e com esse risco, foram identificados os distúrbios: cardiovasculares (43\%); osteomusculares (37\%); respiratórios 
Menezes MR, Oliveira NA, Pedreira LC, Santos EC, Dias ML. A violência doméstica contra o idoso identificada em um de assistência domiciliar: estudo de caso. Rev. Eletr. Enf. [Internet]. 2008;10(4):1050-6. Available from: http://www.fen.ufg. br/revista/v10/n4/v10n4a17.htm.

(14\%); gastrointestinais (4\%); e neuropsiquiátricos $(3 \%)$. Além dessas doenças que, muitas vezes, se sobrepunham em comorbidade, associavam-se situações como: dificuldades de locomoção (40\%); alterações do sono $(28 \%)$ e incontinência urinária $(14 \%)^{(7)}$.

Dessa forma, os idosos mais vulneráveis são os dependentes física e mentalmente. Os maus tratos ocorrem especialmente quando estes apresentam déficits cognitivos, alterações do sono, incontinência e dificuldades de locomoção, necessitando, portanto, de auxílio em suas atividades da vida diária ${ }^{(4)}$.

Em muitos casos, os maus tratos acontecem pelo estresse do cuidador. Esse, com relativa freqüência, além do papel de cuidador, desempenha outras funções domésticas, atividades no trabalho e cuidados com outros membros da família. Além disso, é comum apresentarem também idade avançada e problemas de saúde, tendo que assumir, na maioria das vezes, de modo solitário o idoso dependente ${ }^{(7-12)}$.

Nas reuniões com os cuidadores no PADI, nas visitas domiciliares e em dinâmicas de grupo proporcionadas pelo programa através da enfermagem e psicologia com os familiares, observamos um clima de exaustão destes, quando revelam o enfrentamento de inúmeras dificuldades na vida cotidiana. O estresse destes cuidadores pode desencadear atitudes negligentes, com a prática de agressão física e/ou verbal.

Sobre isso, é visto que o ônus individual e familiar do cuidar do idoso no domicílio, geralmente é dividido com a rede de amigos, vizinhos e colegas de trabalho, que se constituem na rede informal de apoio. Somente quando o cuidado domiciliar se inviabiliza por algum motivo, como no caso de complicações relacionadas à saúde, este é dividido com a rede formal de assistência, por intermédio de ambulatórios, hospitais e asilos ${ }^{(12-13)}$.

Isso ocorre porque no Brasil, não existe um programa governamental direcionado para esta população com dependência. Assim, com a falência do sistema previdenciário, os cuidados prestados no domicílio junto à família vêm se tornando a única opção disponível para o idoso dependente já que, no modelo atual, o
Programa de Saúde da Família não abrange todas as necessidades deste idoso e de sua família $^{(13)}$.

Desse modo, na deficiência de apoios informais ou formais, o cuidador pode ficar exposto a doenças, depressão e estados emocionais negativos, sujeitando o idoso à negligência, abandono e maus tratos ${ }^{(7)}$. No caso 2 , realmente há uma grande sobrecarga do cuidador, associada a dificuldades financeiras.

O Estatuto do Idoso(10), em seu Art.3으, parágrafo Único tópico $V$, mostra que é priorizado o atendimento do idoso por sua própria família em detrimento do atendimento asilar, exceto dos que não a possuam ou careçam de condições de manutenção da própria sobrevivência. Dessa forma, no caso 1 , houve uma recusa familiar em assistir o pai, levando-o a pensar em procurar uma instituição asilar mesmo contra a sua vontade. Contudo, por conta da sua condição de saúde e das dificuldades financeiras, o idoso acabou por voltar a viver no domicílio onde sofreu a violência.

Ainda no Estatuto do Idoso(10) Capítulo II, Art. 99, diz que expor a perigo a integridade e a saúde física ou psíquica do idoso, submetendo-o a condições desumanas ou degradantes ou privando-o de alimentos e cuidados indispensáveis, quando obrigado a fazê-lo, ou sujeitando-o a trabalho excessivo ou inadequado, pode levar a pena de detenção de dois meses a um ano e multa. No caso 2, observamos uma negligência quanto ao cuidado humano, refletido por uma falta de higiene ambiental e da pessoa sujeita dos cuidados.

\section{CONSI DERAÇÕES FI NAIS}

Dos resultados obtidos no trabalho em tela, podemos destacar a experiência adquirida pelos profissionais do PADI, que passaram a identificar melhor os idosos assistidos em situação de risco, e a atuar junto a estes e seus familiares. Das ações implementadas, destacamos a intensificação das visitas ao domicílio e o trabalho mais de perto com os cuidadores, através da atuação da enfermeira e psicóloga, no sentido de orientá-los quanto aos cuidados e de aliviar suas tensões.

Esse trabalho nos levou também a inferir, 
Menezes MR, Oliveira NA, Pedreira LC, Santos EC, Dias ML. A violência doméstica contra o idoso identificada em um de assistência domiciliar: estudo de caso. Rev. Eletr. Enf. [Internet]. 2008; 10(4):1050-6. Available from: http://www.fen.ufg. br/revista/v10/n4/v10n4a17.htm.

que fatores sociais, econômicos, políticos e culturais, a falta de um processo afetivo humano, somado a co-responsabilidade, ao compromisso e à solidariedade intergeracional, podem negligenciar ou privar os idosos do direito de serem cuidados na família.

É assim evidente a necessidade de formação e capacitação de profissionais de saúde para atuar com medidas de prevenção e intervenção junto a esses idosos e seus familiares, a fim de promover a saúde e garantir os direitos fundamentais contidos na Lei.

Torna-se então importante identificar os idosos de risco, para que se possa intervir, acompanhar e/ou encaminhar da melhor forma, respaldando-se nos sinais e sintomas. $O$ acompanhamento dos cuidadores mostrou-se também primordial.

O panorama identificado no estudo é semelhante ao encontrado em outros trabalhos, e ajudou a equipe do PADI a refletir melhor sobre a violência domiciliar contra o idoso, promovendo discussões sobre o tema. Entendemos que as equipes de assistência domiciliar têm um papel fundamental junto a essas ocorrências, pois, na oportunidade da visita, vivencia a situação no contexto domiciliar, podendo identificar os riscos, ao contrário de quem recebe o idoso em serviços de saúde.

\section{REFERÊNCI AS}

1. Menezes MR. Da violência velada à violência silenciada: um estudo etnográfico sobre a violência doméstica contra o idoso [thesis]. Ribeirão Preto: Escola de Enfermagem/USP; 1999. $470 \mathrm{p}$.

2. Silva LMH, Alves DCI, Fernandes LM, Durman S. A violência no idoso. Revista Nursing. 2002; 47(5): 35-41.

3. Organización Panamericana de la Salud. Informe Mundial sobre la violência y la salud. Washington (USA): Organización Mundial de la Salud; 2002

4. Organización Mundial de la Salud. Declaración de Toronto para la Prevención Global del Maltrato de las Personas Mayores. Toronto (Canadá): INPEA/Organización Mundial de la Salud; 2003.

5. Melo VL, Cunha JOC, Falbo Neto GH. Maus- tratos contra idosos no município de Camaragibe, Pernambuco. Rev. Bras. Saude Mater. Infant. [Internet]. 2008 [cited 2008 dec 31];6 Suppl 1:S43-8. Available from: http://www. scielo.br/pdf/rbsmi/v6s1/30503.pdf.

6. Algeri S, Souza L. Intrafamiliar violence against the child: a reflexive analysis. Online Brazilian Journal of Nursing [Internet]. 2005 [cited 2007 dec 31];4(3). Available from: http://www.uff.br/objnursing/index.php/nursing /article/view/40/16.

7. Alves-Mazzotti AJ . Usos e abusos dos estudos de caso. Cad. Pesqui. [Internet]. 2006 [cited 2008 dec 31];36(129):637-51. Available from: http://www. scielo. br/pdf/cp/v36n129/a0736129. pdf.

8. Bardin L. Análise de conteúdo. 3rd ed. Lisboa: Edições 70; 2004.

9. Souza AS, Meira EC, Neri IG, Silva J, Gonsalves LHT. Fatores de risco de maus tratos ao idoso na relação idoso/cuidador em convivência intrafamiliar. Textos Envelhecimento [Internet]. 2004 [cited 2008 dec 31];7(2). Available from: http://www.unati.uerj. br/tse/scielo.php?script= sci arttext\&pid=S1517-

$\underline{59282004000200005 \& l n g=p t \& n r m=i s o}$.

10. Oliveira A. Estatuto do idoso: comentado e completo com a coletânea das normas federais protetivas do idoso. 1st ed. Rio de Janeiro: Imprinta Express; 2004.

11. Souza JAV, Freitas MC de, Queiroz TA de. Violência contra os idosos: análise documental. Rev. bras. enferm. [Internet]. 2007 [cited 2008 dec 31];60(3):268-72. Available from: http://www. scielo.br/pdf/reben/v60n3/a04.pdf.

12. Caldas CP. Envelhecimento com dependência: responsabilidades e demandas da família. Cad. Saúde Pública. 2003; 19(3):733-81 13 Gavião ACD. Aspectos psicológicos e o contexto familiar. In: Duarte YAO, Diogo MJD: Atendimento domiciliar: um enfoque gerontológico. São Paulo: Atheneu; 2005. p.173-80.

Artigo recebido em 20.09.07.

Aprovado para publicação em 31.12.08. 